Using A Priori Contrasts for Multivariate Repeated-Measures ANOVA to Analyze Thermoregulatory Responses of the Dibbler (Parantechinus apicalis; Marsupialia, Dasyuridae) Author(s): Philip C. Withers and Christine E. Cooper

Reviewed work(s):

Source: Physiological and Biochemical Zoology, Vol. 84, No. 5 (September/October 2011), pp. 514-521

Published by: The University of Chicago Press

Stable URL: http://www.jstor.org/stable/10.1086/661637

Accessed: 22/11/2011 19:59

Your use of the JSTOR archive indicates your acceptance of the Terms \& Conditions of Use, available at http://www.jstor.org/page/info/about/policies/terms.jsp

JSTOR is a not-for-profit service that helps scholars, researchers, and students discover, use, and build upon a wide range of content in a trusted digital archive. We use information technology and tools to increase productivity and facilitate new forms of scholarship. For more information about JSTOR, please contact support@jstor.org. 


\section{Using A Priori Contrasts for Multivariate Repeated-Measures ANOVA to Analyze Thermoregulatory Responses of the Dibbler (Parantechinus apicalis; Marsupialia, Dasyuridae)}

\author{
Philip C. Withers ${ }^{\star}$ \\ Christine E. Cooper \\ Animal Biology M092, University of Western Australia, \\ Stirling Highway, Crawley, Western Australia 6009, Australia; \\ and Department of Environment and Agriculture, Curtin \\ University, P.O. Box U1987 Perth, Western Australia 6845, \\ Australia
}

Accepted 5/16/2011; Electronically Published 8/24/2011

Online enhancement: Excel file.

\begin{abstract}
Physiological studies often involve the repeated measurement of individuals over a range of ordered categorical conditions, for example, varying ambient temperature. We illustrate here the use of a priori contrasts for multivariate repeated-measures ANOVA by analyzing the thermal responses of various physiological variables for a small marsupial, the dibbler (Parantechinus apicalis). Our analyses showed that dibblers conform closely to the Scholander-Irving model of endothermy. Body temperature was constant at low air temperatures, was $36.3 \pm 0.24^{\circ} \mathrm{C}$ at thermoneutrality $\left(30^{\circ} \mathrm{C}\right)$, and increased at $35^{\circ} \mathrm{C}$. Metabolic rate decreased with increasing ambient temperature to a basal rate of $0.619 \pm 0.036 \mathrm{~mL} \mathrm{O}_{2} \mathrm{~g}^{-1} \mathrm{~h}^{-1}$ at $30^{\circ} \mathrm{C}$; it extrapolated closely to thermoneutral body temperature. Increased oxygen demand at lower ambient temperature was met by increased respiratory minute volume, achieved by increased respiratory frequency and tidal volume; oxygen extraction was constant at about 19\%. Evaporative water loss and wet and dry thermal conductance increased markedly at high ambient temperatures but not sufficiently to maintain constant body temperature. Relative water economy was similar to that of other small marsupials, increasing linearly at lower air temperatures with a point of relative water economy of $20.3^{\circ} \mathrm{C}$. We conclude that a priori contrasts provide a statistically appropriate and powerful analysis that can be used routinely to statistically describe the pattern of response of
\end{abstract}

\footnotetext{
*Corresponding author; e-mail: philip.withers@uwa.edu.au.
}

Physiological and Biochemical Zoology 84(5):514-521. 2011. (C) 2011 by The University of Chicago. All rights reserved. 1522-2152/2011/8405-1014\$15.00. DOI: $10.1086 / 661637$ physiological variables to a categorical factor and are especially useful for repeated-measures ANOVA designs common to many physiological studies.

\section{Introduction}

A priori contrasts provide a powerful tool to evaluate expected patterns with a categorical factor for ANOVA (Cohen 2008), univariate repeated-measures ANOVA (Potvin et al. 1990; Park et al. 2009), and multivariate repeated-measures ANOVA (Rencher 2002), because they examine specific hypotheses using an appropriate contrast matrix (e.g., Bock 1975; Hand and Taylor 1987). For example, a simple contrast tests whether a control category is different from each other category. For ordered categorical data, a Helmert contrast tests whether a category is different from all subsequent categories pooled together; a reverse-Helmert contrast tests whether a category is different from all previous categories pooled. For ordered numeric categories (e.g., ambient temperature $T_{\mathrm{a}}$ measured in ${ }^{\circ} \mathrm{C}$ ), a polynomial contrast examines whether there is a linear, quadratic, or other polynomial relationship. A priori contrasts can be more powerful than the overall ANOVA hypothesis (that all means are equal) because they address more specific hypotheses than general post hoc tests and because they address fewer specific uncorrelated hypotheses (e.g., experimental groups differ from a control group, or there is a linear relationship for ordered categories). However, contrast tests have not been widely embraced by comparative physiologists despite their usefulness for examining specific patterns in physiological data sets and especially their particular value in overcoming the issue of an absence of post hoc tests for repeated-measures ANOVA.

Many physiological studies involve the repeated measurement of individuals subjected to different categorical treatments on an ordered scale, for example, measurement of a physiological variable at different ambient temperatures. Multivariate repeated-measures analysis of variance (MANOVAR) is an appropriate statistical analysis for such data, with the repeated measure (e.g., $T_{\mathrm{a}}$ ) being the multivariate factor (Potvin et al. 1990; Rencher 2002; Park et al. 2009). However, a major limitation of MANOVAR is that it does not have formal comparison tests equivalent to ANOVA post hoc tests (e.g. Tukey, Dunnett, Student-Newman-Keuls, etc). Consequently, it is difficult to statistically discern the pattern of the effect of a sig- 
nificant repeated factor (e.g., the pattern of a $T_{\mathrm{a}}$ effect for a physiological variable) within the MANOVAR model. The recent physiological literature includes various approaches to this problem. Some repeated-measures studies simply do not evaluate the pattern of the repeated measure (e.g., Beaupre and Zaidan 2001; Gomez et al. 2006), and some use a Bonferronitype adjustment for multiple comparison tests (e.g., Rezende et al. 2004; Berg and Biewener 2008; Park et al. 2009; Wu et al. 2009; Dunlap et al. 2010) or post hoc ANOVA tests that do not account for repeated measurements (e.g., McLean and Speakman 2000; Gilmour et al. 2001; Zerm et al. 2004; Zhao and Cao 2009; Dupont-Prinet et al. 2010).

We illustrate here the use of a priori contrasts, by examining the thermoregulatory responses of the dibbler (Parantechinus apicalis), a 40-100-g endangered dasyurid marsupial characterized by a white eye ring and freckled fur (Woolley 2008). The dibbler's current distribution is restricted to three small islands near Jurien, Western Australia, and a few scattered mainland sites on the south coast of Western Australia, where it inhabits dense heath on sandy soils (Menkhorst and Knight 2004; Cronin 2008; Woolley 2008). We characterize body temperature, metabolic rate, thermal conductance, respiratory ventilation, evaporative water loss, and relative water economy over a range of ambient temperatures and then examine the various patterns of $T_{\mathrm{a}}$ effects below and above thermoneutrality using a priori contrasts and MANOVAR (Rencher 2002), based on the typical responses of endotherms (e.g., McNab 1980; Withers 1992) and more specifically of other dasyurid marsupials (e.g., Dawson and Wolfers 1978; Morton and Lee 1978; Geiser 1986; Geiser and Baudinette 1988; Hallam and Dawson 1993; Larcombe 2002; Schmidt et al. 2009; Cooper and Withers 2010; Warnecke et al. 2010). We use polynomial contrasts to examine linear changes with $T_{\mathrm{a}}$, as might be expected for metabolic rate (MR), ventilatory variables including respiratory rate $\left(f_{\mathrm{R}}\right)$, tidal volume $\left(V_{\mathrm{T}}\right)$ and minute volume $\left(V_{\mathrm{I}}\right)$, and possibly evaporative water loss (EWL). We use simple contrasts to compare thermoneutrality with the other $T_{\mathrm{a}}$ treatments and Helmert and reverse-Helmert contrasts to identify a pattern of relative constancy but an increase at low or high $T_{\mathrm{a}}$, as might be expected for body temperature $\left(T_{\mathrm{b}}\right)$, wet $\left(C_{\text {wet }}\right)$ and dry $\left(C_{\text {dry }}\right)$ thermal conductance, and possibly EWL.

\section{Material and Methods}

\section{Animals}

Eight dibblers (four male, four female) were studied at Perth Zoo, Western Australia $\left(31^{\circ} 58^{\prime} \mathrm{S}, 115^{\circ} 51^{\prime} \mathrm{E}\right)$, during August/September 2009. One individual was wild caught at Fitzgerald River National Park $\left(34^{\circ} 4^{\prime} \mathrm{S}, 119^{\circ} 25^{\prime} \mathrm{E}\right)$, and the others were captiveborn descendants of other individuals from this location. Dibblers were housed indoors in individual cages with a natural photoperiod and were fed a diet of minced meat, ground cat biscuits, boiled eggs, and Wombaroo small-carnivore food, along with baby rats, crickets, and mealworms, with water ad lib.

\section{Respirometry}

Metabolic rate (oxygen consumption, $\mathrm{Vo}_{2}$; carbon dioxide production, $\mathrm{VCO}_{2}$ ) and EWL were measured by flow-through respirometry for individuals that had been fasted for $20 \mathrm{~h}$ before the commencement of experiments. Dibblers were measured for 5-9 $\mathrm{h}$ at each $T_{\mathrm{a}}$ during their inactive phase (day) until $\mathrm{VO}_{2}, \mathrm{VCO}_{2}$, and EWL were stable and minimal; individuals were measured at only one $T_{\text {a }}$ per day and not more frequently than every 3 days. Observations of dibblers in the metabolic chamber by video indicated when dibblers were resting and asleep; these periods were easily identified in the continuous traces of physiological data and used for analysis, so we are confident that our values are for resting, inactive dibblers. $T_{\mathrm{b}}$ was measured when dibblers were removed from the chamber at the end of the experiment, using a plastic-tipped thermocouple (connected to a Radio Spares 611-234 thermocouple meter) inserted $\sim 1.5 \mathrm{~cm}$ into the cloaca.

Mass flow controllers (Aalborg GFC17 and Cole-Palmer 32708-26) regulated the flow of ambient air at a constant rate of 500-700 $\mathrm{mL} \mathrm{min}^{-1}$ through cylindrical glass chambers $(500$ $\mathrm{mL}$ ), located in a temperature-controlled cabinet. Individuals were measured at each ambient temperature $\left(T_{\mathrm{a}}: 9.4^{\circ}, 15.3^{\circ}\right.$, $19.9^{\circ}, 25.3^{\circ}, 30.8^{\circ}$, and $35.3^{\circ} \mathrm{C}$ ) in random order for independence of data from the order of measurement. Excurrent air passed over a thin-film-capacitance relative humidity $(\mathrm{RH})$ and $T_{\text {a }}$ probe (Vaisala HMP45A), with a subsample passing through a column of Drierite (W. A. Hammond Drierite) and then an oxygen analyzer (Sable Systems FoxBox or Servomex 574) and a carbon dioxide analyzer (Sable Systems FoxBox or CA-2A). The data were recorded by a PC every $20 \mathrm{~s}$ throughout the experimental period using custom-written Visual Basic (v6) software, via the serial port of the Sable Systems FoxBox or a Pico Technology ADC11 A/D converter. A custom-written Visual Basic program was used for metabolic and hygric calculations (after Withers 2001).

Ventilatory data were measured by whole-body plethysmography (Malan 1973; Withers 1977; Szewczak and Powell 2003), whereby pressure changes in the metabolic chamber due to respiration were detected with a custom-made pressure transducer (Motorola MPX2010 sensor). The voltage output from the pressure transducer was monitored using a Pico Technology ADC11 A/D converter and was recorded on a PC every $15 \mathrm{~ms}$ for approximately $30 \mathrm{~s}$ using PicoScope. Between two and six sets of ventilatory data were obtained for an individual dibbler at each $T_{a}$, and a single mean was calculated for each ventilatory variable for each individual at each $T_{\mathrm{a}}$. Ventilatory measurements were made toward the end of each experiment, when a low stable metabolic rate and video observation confirmed that the dibbler was quiet and resting. A custom-written Visual Basic program was used for ventilatory calculations (after Malan 1973; Szewczak and Powell 2003). Ventilatory variables are presented at body temperature and pressure saturated (втPS) conditions. Oxygen extraction $\left(E_{2}\right)$ was calculated using the standard temperature and pressure dry (STPD) values for $\mathrm{Vo}_{2}$ and $V_{\mathrm{I}}$ at the time of ventilatory measurements, using 
a fractional inspired oxygen content calculated as the mean of 0.2095 and the measured fractional excurrent oxygen at the time of ventilatory measurements.

The FoxBox oxygen analyzer was two-point calibrated by its electronic zero function and dry ambient air (20.95\%) and the Servomex with compressed $\mathrm{N}_{2}$ and dry ambient air. Carbon dioxide analyzers were calibrated with compressed $\mathrm{N}_{2}$ and a certified gas $\operatorname{mix}\left(0.53 \% \mathrm{CO}_{2}\right)$. The calibration of the relative humidity probes was confirmed using $1 \% \mathrm{RH}$ air (dried with Drierite) and $100 \% \mathrm{RH}$ air (saturated; by breathing on the RH probe). Flowmeters were calibrated using a bubble flowmeter (Bubble-O-Meter). The plethysmography system was calibrated by injecting known air volumes $(0.3-0.5 \mathrm{~mL})$ into the chamber and then accounting for the pressure decay characteristics (i.e., mathematically converting the open-system measurement to a closed system; see Szewczak and Powell 2003).

Respiratory exchange ratio (RER) was calculated as $\mathrm{VCO}_{2} / \mathrm{VO}_{2}$, and $C_{\text {wet }}\left(\mathrm{J} \mathrm{g}^{-1} \mathrm{~h}^{-1}{ }^{\circ} \mathrm{C}^{-1}\right)$ was calculated from metabolic heat production (MHP; converted from MR using the measured RER, by interpolation from Table 4.2 in Withers 1992) as $\mathrm{MHP} /\left(T_{\mathrm{b}}-T_{\mathrm{a}}\right)$. $C_{\mathrm{dry}}\left(\mathrm{J} \mathrm{g}^{-1} \mathrm{~h}^{-1}{ }^{\circ} \mathrm{C}^{-1}\right)$ was calculated as $(\mathrm{MHP}-\mathrm{EHL}) /\left(T_{\mathrm{b}}-T_{\mathrm{a}}\right)$, where evaporative heat loss (EHL) waw converted from EWL assuming $2.4 \mathrm{~J} \mathrm{mg}^{-1} \mathrm{H}_{2} \mathrm{O}(\mathrm{McNab}$ 2002). Metabolic water production (MWP; $\mathrm{mg} \mathrm{g}^{-1} \mathrm{~h}^{-1}$ ) was also calculated from MR using the measured RER after Withers (1992). Relative water economy (RWE) was calculated as MWP/ EWL and the point of relative water economy (PRWE) as the $T_{\mathrm{a}}$ at which RWE interpolated to 1 .

\section{Statistics}

Values are presented as mean \pm standard error, with $N=8$ individuals. Basic statistical analyses were conducted with statistiXL (v1.8). Effects of $T_{\mathrm{a}}$ on physiological variables were examined using MANOVAR, with the eight dibblers as replicates and $T_{\mathrm{a}}$ as the repeated measure (Rencher 2002). We examined various a priori contrasts, depending on the expected $T_{\text {a }}$ pattern, including linear, quadratic, and cubic polynomial contrasts, simple contrasts for comparing a specified group with each other group, and Helmert and reverse-Helmert contrasts for sequential comparisons of categories with all previous or subsequent $T_{\mathrm{a}}$ categories.

The $t$ statistic for an a priori contrast was calculated for each row of the contrast matrix $(\mathrm{C})$ as

$$
t_{i}=\frac{n^{0.5} \mathbf{c}_{i}^{\mathrm{T}} \overline{\mathbf{y}}}{\left(\mathbf{c}_{i}^{\mathrm{T}} \mathbf{S} \mathbf{c}_{i}\right)^{0.5}},
$$

where $n$ is the number of subjects, $\mathbf{c}_{i}$ is a row and $\mathbf{c}_{i}^{\mathrm{T}}$ is the transpose of a row of the contrast matrix, $\bar{y}$ is a vector consisting of the means for each repeated category, and $\mathbf{S}$ is the covariance matrix (which can be obtained from various statistical procedures in many statistics packages, e.g., from principal component analysis in statistiXL); the test statistic has $n-1$ degrees of freedom (Rencher 2002). Contrast tests were accomplished in an Excel spreadsheet using a custom-written a priori contrast macro, based on Rencher (2002); this spreadsheet is available in an Excel file in the online edition of Physiological and Biochemical Zoology. Simple, Helmert and reverse-Helmert contrast matrices were calculated after Bock (1975) and Hand and Taylor (1987). Polynomial contrast matrices were calculated for unequally spaced repeated measures (Robson 1959). The contrast matrices for our data set with $T_{\mathrm{a}}=9.4^{\circ}, 15.3^{\circ}, 19.9^{\circ}, 25.3^{\circ}$, $30.8^{\circ}$, and $35.3^{\circ} \mathrm{C}$ are shown in Table 1 .

\section{Results}

Mean body mass of the dibblers was 78.3 $\pm 5.1 \mathrm{~g}(N=8)$. There were mass differences between individuals (range 63.5$\left.99.3 \mathrm{~g} ; F_{7,40}=204, P<0.001\right)$, but there was no change in mass of individuals over the five measurements $\left(F_{5,3}=6.25, P=\right.$ $0.081)$.

Observations of dibblers in the metabolic chamber indicated that they rested and appeared to be asleep for most of the time, except for occasional short periods of activity (e.g., grooming) that corresponded to increased $\mathrm{VO}_{2}, \mathrm{VCO}_{2}$ and EWL. The dibblers were curled up with erect fur at low $T_{a}$, and their fur was more depressed and posture more stretched out as $T_{\mathrm{a}}$ increased. None of the dibblers entered torpor, defined as $\mathrm{VO}_{2}<75 \%$ of basal metabolic rate (BMR) at any $T_{a}$ (Geiser and Baudinette 1988).

Dibblers' $T_{\mathrm{b}}$ ranged from $36.3^{\circ} \pm 0.2^{\circ} \mathrm{C}$ at $T_{\mathrm{a}}=9^{\circ} \mathrm{C}$ to $37.7^{\circ} \pm 0.2^{\circ} \mathrm{C}$ at $T_{\mathrm{a}}=35^{\circ} \mathrm{C}$ (Fig. 1). Individuals did not differ with respect to $T_{\mathrm{b}}\left(F_{7,40}=0.84, P=0.558\right)$, but there was a significant effect of $T_{\mathrm{a}}\left(F_{5,3}=13.1, P=0.030\right)$. Excluding the $T_{\mathrm{a}}=35^{\circ} \mathrm{C}$ data removed the $T_{\mathrm{a}}$ effect $\left(F_{4,4}=0.316, P=\right.$ $0.855)$, suggesting a pattern of higher $T_{\mathrm{b}}$ at $T_{\mathrm{a}}=35^{\circ} \mathrm{C}$ compared with all other $T_{\mathrm{a}}$ 's. A priori contrasts supported this pattern. Linear $(P=0.002)$, quadratic $(P=0.046)$, and cubic contrasts $(P=0.015)$ were significant when $T_{\mathrm{a}}=35^{\circ} \mathrm{C}$ data were included, but not when $T_{\mathrm{a}}=35^{\circ} \mathrm{C}$ data were excluded ( $P \geq 0.379$ ), indicating that the $T_{\mathrm{a}}=35^{\circ} \mathrm{C}$ data differed from $T_{\mathrm{b}}$ at the other $T_{\mathrm{a}}$ 's. Similarly, Helmert contrasts were significant only for comparison of $T_{\mathrm{a}}=31^{\circ} \mathrm{C}$ with $T_{\mathrm{a}}=35^{\circ} \mathrm{C} \quad(P=$ $0.004)$, and the only significant reverse Helmert contrast was for comparison of $T_{\mathrm{a}}=35^{\circ} \mathrm{C}$ with all of the lower $T_{\mathrm{a}}$ 's $(P<$ $0.001)$. The thermolability of $T_{\mathrm{b}}\left(\Delta T_{\mathrm{b}} / \Delta T_{\mathrm{a}}\right)$ was $-0.00042^{\circ} \mathrm{C}$ ${ }^{\circ} \mathrm{C}^{-1}$ from $T_{\mathrm{a}}=9^{\circ}$ to $31^{\circ} \mathrm{C}$ (MANOVAR linear contrast); it was $+0.283^{\circ} \pm 0.067^{\circ} \mathrm{C}^{\circ} \mathrm{C}^{-1}$ from $T_{\mathrm{a}}=31^{\circ}$ to $35^{\circ} \mathrm{C}$.

The $\mathrm{VO}_{2}$ of dibblers decreased from $2.65 \pm 0.12 \mathrm{~mL} \mathrm{O}_{2} \mathrm{~g}^{-1}$ $\mathrm{h}^{-1}$ at $T_{\mathrm{a}}=9^{\circ} \mathrm{C}$ to a minimum of $0.619 \pm 0.036 \mathrm{~mL} \mathrm{O}_{2} \mathrm{~g}^{-1}$ $\mathrm{h}^{-1}(n=8)$ at $T_{\mathrm{a}}=31^{\circ} \mathrm{C}$ (Fig. 1$)$; we consider this minimal value at $31^{\circ} \mathrm{C}$ to be $\mathrm{BMR}$. There were no differences in $\mathrm{Vo}_{2}$ between individuals $\left(F_{7,40}=0.131, P=0.995\right)$, but there was a significant effect of $T_{\mathrm{a}}\left(F_{5,3}=58.2, P=0.004\right)$. The pattern of $\mathrm{VO}_{2}$ with $T_{\mathrm{a}}$ (Fig. 1) suggests that $\mathrm{VO}_{2}$ decreased linearly with increasing $T_{\mathrm{a}}$ but increased at $T_{\mathrm{a}}=35^{\circ} \mathrm{C}$. Polynomial a priori contrasts confirmed this pattern. Linear $(P<0.001)$, quadratic $(P=0.001)$, and cubic $(P=0.029)$ polynomials were significant when $T_{\mathrm{a}}=35^{\circ} \mathrm{C}$ data were included, but there was only a significant linear pattern $(P<0.001)$ when $T_{\mathrm{a}}=35^{\circ} \mathrm{C}$ data were omitted ( $P \geq 0.475$ for quadratic and cubic contrasts), 
Table 1: Contrast matrices used for a priori comparison tests of dibbler physiological variables at ambient temperatures $\left(T_{\mathrm{a}}\right.$ 's $)$ of $9.4^{\circ}, 15.3^{\circ}, 19.9^{\circ}$, $25.3^{\circ}, 30.8^{\circ}$, and $35.3^{\circ} \mathrm{C}$

\begin{tabular}{|c|c|c|c|c|c|c|}
\hline \multirow[b]{2}{*}{ Contrast } & \multicolumn{6}{|l|}{$T_{\mathrm{a}}\left({ }^{\circ} \mathrm{C}\right)$} \\
\hline & 9.4 & 15.3 & 19.9 & 25.3 & 30.8 & 35.3 \\
\hline \multirow[t]{5}{*}{ Simple } & 1 & 0 & 0 & 0 & -1 & 0 \\
\hline & 0 & 1 & 0 & 0 & -1 & 0 \\
\hline & 0 & 0 & 1 & 0 & -1 & 0 \\
\hline & 0 & 0 & 0 & 1 & -1 & 0 \\
\hline & 0 & 0 & 0 & 0 & -1 & 1 \\
\hline \multirow[t]{5}{*}{ Helmert } & 1 & $-1 / 5$ & $-1 / 5$ & $-1 / 5$ & $-1 / 5$ & $-1 / 5$ \\
\hline & 0 & 1 & $-1 / 4$ & $-1 / 4$ & $-1 / 4$ & $-1 / 4$ \\
\hline & 0 & 0 & 1 & $-1 / 3$ & $-1 / 3$ & $-1 / 3$ \\
\hline & 0 & 0 & 0 & 1 & $-1 / 2$ & $-1 / 2$ \\
\hline & 0 & 0 & 0 & 0 & 1 & -1 \\
\hline \multirow[t]{5}{*}{ Reverse Helmert } & -1 & 1 & 0 & 0 & 0 & 0 \\
\hline & $-1 / 2$ & $-1 / 2$ & 1 & 0 & 0 & 0 \\
\hline & $-1 / 3$ & $-1 / 3$ & $-1 / 3$ & 1 & 0 & 0 \\
\hline & $-1 / 4$ & $-1 / 4$ & $-1 / 4$ & $-1 / 4$ & 1 & 0 \\
\hline & $-1 / 5$ & $-1 / 5$ & $-1 / 5$ & $-1 / 5$ & $-1 / 5$ & 1 \\
\hline \multicolumn{7}{|l|}{ Polynomial: } \\
\hline Linear & -13.3 & -7.4 & -2.8 & 2.6 & 8.1 & 12.6 \\
\hline Quadratic & 92.4 & -27.0 & -71.9 & -70.5 & -9.1 & 86.1 \\
\hline Cubic & -379.9 & 594.5 & 288.6 & -403.0 & -547.6 & 447.4 \\
\hline
\end{tabular}

Note. Contrasts: simple compares a specified category with all other categories (specified group is $30.8^{\circ} \mathrm{C}$ ), Helmert tests whether a category is different from all subsequent categories pooled together, reverse Helmert tests whether a category is different from all previous categories pooled, and polynomial test is for an ordered pattern such as a linear or quadratic relationship for a variable with categories on a numeric scale.

indicating that $\mathrm{VO}_{2}$ decreased linearly with $T_{\mathrm{a}}$ to $31^{\circ} \mathrm{C}$; it did not increase significantly at $T_{\mathrm{a}}=35^{\circ} \mathrm{C}$ ( simple contrast $P=$ 0.128). The linear relationship (excluding $T_{\mathrm{a}}=35^{\circ} \mathrm{C}$ ) was $\mathrm{VO}_{2}=3.44-0.095 T_{\mathrm{a}}$, which extrapolates to a predicted $T_{\mathrm{b}}$ of $36.2^{\circ} \mathrm{C}$. The pattern in $\mathrm{VCO}_{2}$ was similar to that of $\mathrm{Vo}_{2}$ and is therefore not analyzed or presented separately. The RER was independent of individual $\left(F_{7,40}=1.34, P=0.258\right)$ and $T_{\mathrm{a}}$ $\left(F_{5,3}=5.88, P=0.088\right.$ ), at $0.72 \pm 0.015$ (mean for all $6 T_{\mathrm{a}}$ 's).

Dibblers' $C_{\text {wet }}$ varied little from $T_{\mathrm{a}}=9^{\circ} \mathrm{C}\left(1.93 \pm 0.083 \mathrm{~J} \mathrm{~g}^{-1}\right.$ $\left.\mathrm{h}^{-1}{ }^{\circ} \mathrm{C}^{-1}\right)$ to $25^{\circ} \mathrm{C}\left(1.77 \pm 0.085 \mathrm{~J} \mathrm{~g}^{-1} \mathrm{~h}^{-1}{ }^{\circ} \mathrm{C}^{-1}\right)$, then increased slightly at $31^{\circ} \mathrm{C}\left(2.27 \pm 0.15 \mathrm{~J} \mathrm{~g}^{-1} \mathrm{~h}^{-1}{ }^{\circ} \mathrm{C}^{-1}\right)$ and substantially at $35^{\circ} \mathrm{C}$ to $6.51 \pm 0.70 \mathrm{~J} \mathrm{~g}^{-1} \mathrm{~h}^{-1}{ }^{\circ} \mathrm{C}^{-1}$ (Fig. 1). There was no difference in $C_{\text {wet }}$ between individuals $\left(F_{7,40}=0.099, P=\right.$ $0.998)$, but there was a significant effect of $T_{\mathrm{a}}\left(F_{5,3}=130\right.$, $P=0.001)$. There were highly significant linear, quadratic, and cubic patterns $(P<0.001)$ for all $T_{\mathrm{a}}$ 's but no linear $(P=$ $0.200)$, quadratic $(P=0.060)$, or cubic effects $(P=0.140)$ for $T_{\mathrm{a}} \leq 31^{\circ} \mathrm{C}$. This pattern was supported by reverse Helmert contrasts being significant for $C_{\text {wet }}$ only at $35^{\circ} \mathrm{C}(P<0.001)$ and $31^{\circ} \mathrm{C}(P=0.037)$ compared to lower $T_{\mathrm{a}}$ 's, and significant Helmert contrasts for all $T_{\mathrm{a}}$ 's $(P<0.0012) . C_{\mathrm{dry}}$ was constant from $T_{\mathrm{a}}=9^{\circ} \mathrm{C}\left(1.84 \pm 0.081 \mathrm{~J} \mathrm{~g}^{-1} \mathrm{~h}^{-1}{ }^{\circ} \mathrm{C}^{-1}\right)$ to $31^{\circ} \mathrm{C}(1.89 \pm$ $0.135 \mathrm{~J} \mathrm{~g}^{-1} \mathrm{~h}^{-1}{ }^{\circ} \mathrm{C}^{-1}$ ) and then increased substantially at $T_{\mathrm{a}}=35^{\circ} \mathrm{C}$ to $4.74 \pm 0.56 \mathrm{~J} \mathrm{~g}^{-1} \mathrm{~h}^{-1}{ }^{\circ} \mathrm{C}^{-1}$ (Fig. 1 ). There was no difference in $C_{\mathrm{dry}}$ between individuals $\left(F_{7,40}=0.148, P=\right.$
0.993), but there was a significant effect of $T_{\mathrm{a}}\left(F_{5,3}=154\right.$, $P<0.001)$. As for $C_{\text {wet, }}$, there were highly significant linear, quadratic, and cubic effects $(P<0.003)$ for all $T_{\mathrm{a}}$ 's but no linear, quadratic, or cubic effects $(P>0.186)$ for $T_{\mathrm{a}} \leq 31^{\circ} \mathrm{C}$. This pattern was supported by the reverse Helmert contrast being significant only for $C_{\text {dry }}$ at $35^{\circ} \mathrm{C}$ compared to lower $T_{a}(P=$ 0.002 ) and significance for all Helmert contrasts of $C_{\mathrm{dry}}$ for all $T_{\mathrm{a}}$ 's $(P<0.003)$ at $35^{\circ} \mathrm{C}$ compared to lower $T_{\mathrm{a}}$ 's $(P<0.003)$.

Individual dibblers did not differ with respect to EWL $\left(F_{7,40}=1.63, P=0.155\right)$ and there was no overall $T_{\mathrm{a}}$ effect by $\operatorname{MANOVAR}\left(F_{5,3}=4.07, P=0.139\right)$. However, examination of the pattern of EWL with $T_{\mathrm{a}}$ suggests that EWL decreased from $T_{a}=9^{\circ}$ to $31^{\circ} \mathrm{C}$, then increased to the highest value of $1.65 \pm 0.12 \mathrm{mg} \mathrm{H}_{2} \mathrm{O} \mathrm{g}^{-1} \mathrm{~h}^{-1}$ at $35^{\circ} \mathrm{C}$ (Fig. 2). A priori contrasts indicated a significant linear $(P=0.043)$, quadratic $(P=$ $0.001)$ and cubic $(P=0.003)$ effect over all $T_{\mathrm{a}}$ 's but only a significant linear effect $(P=0.016)$ if $T_{\mathrm{a}}=35^{\circ} \mathrm{C}$ was excluded. This suggests a negative linear effect of $T_{\mathrm{a}}$ on EWL from $9^{\circ} \mathrm{C}$ $\left(1.10 \pm 0.10 \mathrm{mg} \mathrm{g}^{-1} \mathrm{~h}^{-1}\right)$ to $31^{\circ} \mathrm{C}\left(0.86 \pm 0.065 \mathrm{mg} \mathrm{g}^{-1} \mathrm{~h}^{-1}\right)$ and a marked increase in EWL at $T_{\mathrm{a}}=35^{\circ} \mathrm{C}$. The linear relationship (excluding $T_{\mathrm{a}}=35^{\circ} \mathrm{C}$ ) was $\mathrm{EWL}=1.31-0.017 T_{\mathrm{a}}$. EWL was also significantly higher at $T_{\mathrm{a}}=35^{\circ} \mathrm{C}$ than all lower $T_{\mathrm{a}}$ 's (simple and reverse Helmert contrasts, $P<0.001$ ) and EWL at $20^{\circ}, 25^{\circ}$ and $31^{\circ} \mathrm{C}$ was lower than at $35^{\circ} \mathrm{C}$ by Helmert contrasts $(P<0.037)$. 


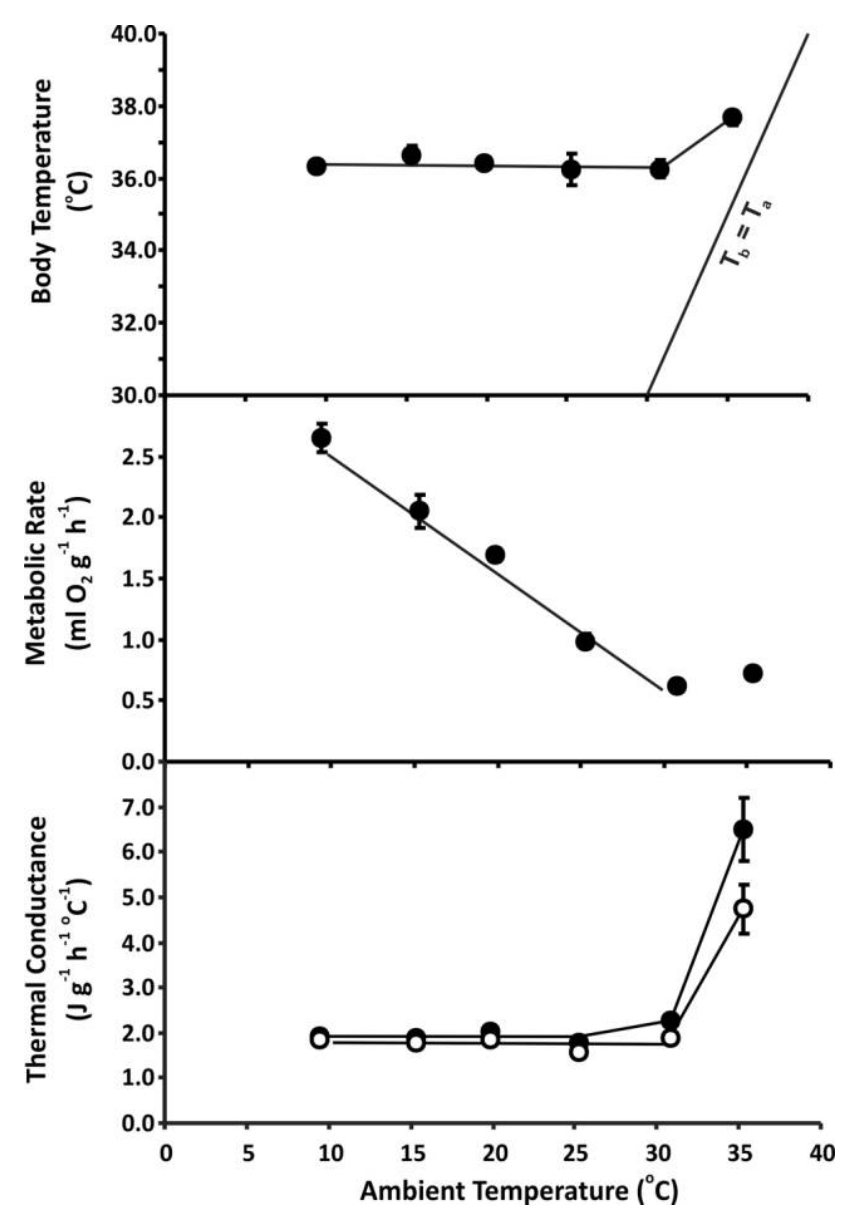

Figure 1. Body temperature, metabolic rate, and wet (black symbols) and dry (white symbols) thermal conductance of dibblers (Parantechinus apicalis) at a range of ambient temperatures. Solid lines indicate patterns supported by a priori contrast analysis (see text). Values are mean \pm standard error; $N=8$.

RWE (Fig. 2) decreased significantly with $T_{\mathrm{a}}\left(F_{5,3}=34.2\right.$, $P=0.008)$, from $1.45 \pm 0.13$ at $T_{\mathrm{a}}=9^{\circ} \mathrm{C}$ to $0.26 \pm 0.04$ at $35^{\circ} \mathrm{C}$ but did not differ between individuals $\left(F_{7,40}=0.501\right.$, $P=0.828)$. The pattern was highly linear for all $T_{\mathrm{a}}$ 's $(P<$ $0.001)$ but not quadratic or cubic $(P>0.085)$; RWE $=$ $1.92-0.052 T_{\mathrm{a}}$, and PRWE $=20.3^{\circ} \mathrm{C}$.

There was a significant effect of $T_{\mathrm{a}}$ on $f_{\mathrm{R}}, V_{\mathrm{T}}$, and $V_{\mathrm{I}}$ (Fig. 3; $\left.F_{5,3} \geq 10.5, P \leq 0.041\right)$, but not on $E_{\mathrm{O}_{2}}\left(F_{5,3}=0.552, P=\right.$ 0.738 ), with no differences between individual dibblers for any respiratory variable $\left(F_{7,40} \leq 1.70, P \geq 0.138\right)$. Contrasts indicated linear $(P<0.001)$ and quadratic $(P=0.023)$ components for the effect of all $T_{\mathrm{a}}$ 's on $f_{\mathrm{R}}$ but only a linear component when $T_{\mathrm{a}}=35^{\circ} \mathrm{C}$ was excluded $\left(f_{\mathrm{R}}=105-2.59 T_{\mathrm{a}} ; P<0.001\right) ; f_{\mathrm{R}}$ increased significantly from $31^{\circ}$ to $35^{\circ} \mathrm{C}$ (simple contrast $P=$ 0.018). $V_{\mathrm{T}}$ decreased linearly from $T_{\mathrm{a}}=9.4^{\circ} \mathrm{C}(2.10 \pm 0.259$ $\mathrm{mL})$ to $T_{\mathrm{a}}=35^{\circ} \mathrm{C}(1.01 \pm 0.55 \mathrm{~mL}) ; V_{\mathrm{T}}=2.46-0.044 T_{\mathrm{a}}$ $(P=0.003)$ for all $T_{\mathrm{a}}$ 's, with no significant quadratic effect $(P=0.790)$. For $V_{\mathrm{I}}$ there was a significant $(P<0.001)$ linear decline from $9^{\circ} \mathrm{C}\left(166.4 \pm 25.5 \mathrm{~mL} \mathrm{~min}^{-1}\right)$ to $31^{\circ} \mathrm{C}(27.7 \pm$
$2.09 \mathrm{~mL} \mathrm{~min}^{-1}$ ) for both $T_{\mathrm{a}} \leq 31^{\circ} \mathrm{C}$ and $T_{\mathrm{a}} \leq 35^{\circ} \mathrm{C}$ but no significant quadratic or cubic contrasts $(P>0.071)$. For $T_{\mathrm{a}} \leq 31^{\circ} \mathrm{C}$, $V_{\mathrm{I}}=196-5.49 T_{\mathrm{a}} . V_{\mathrm{I}}$ was not significantly different between $31^{\circ}$ and $35^{\circ} \mathrm{C}$ (simple contrast $P=0.227$ ). There were no significant polynomial contrasts for $E_{2}(P>0.350)$ and no decrease in $E \mathrm{O}_{2}$ at $T_{\mathrm{a}}=35^{\circ} \mathrm{C}$ compared to the lower $T_{\mathrm{a}}$ 's (reverse Helmert $P=0.440$ ); mean $E \mathrm{O}_{2}$ was $19.3 \% \pm 0.5 \%$ over all $T_{\mathrm{a}}$ 's.

\section{Discussion}

This study of the thermal, metabolic, hygric, and ventilatory physiology of the dibbler follows a repeated-measures experimental design that is common in physiological (and many other) studies, that is, the measurement of a parameter (e.g., metabolic rate) repeated for the same individuals over a range of ordered categorical experimental conditions (e.g., $T_{\mathrm{a}}$ ). We demonstrate here the power of a priori contrasts in a multivariate repeated-measures analysis in the absence of post hoc tests, by examining specific hypotheses for thermal patterns in the first physiological data available for dibblers. This approach enables us to describe the presence as well as statistically confirming the pattern of physiological responses with $T_{\mathrm{a}}$ for this endangered dasyurid marsupial.

MANOVAR consistently found significant effects for those physiological variables that we anticipated would be influenced by $T_{\mathrm{a}}$, that is, $T_{\mathrm{b}}, \mathrm{VO}_{2}, C_{\text {wet }}, C_{\text {dry }}, \mathrm{RWE}, f_{\mathrm{R}}, V_{\mathrm{T}}$, and $V_{\mathrm{I}}$. An overall $T_{\mathrm{a}}$ effect was insignificant for EWL and $E_{2}$, but a $T_{\mathrm{a}}$ effect is

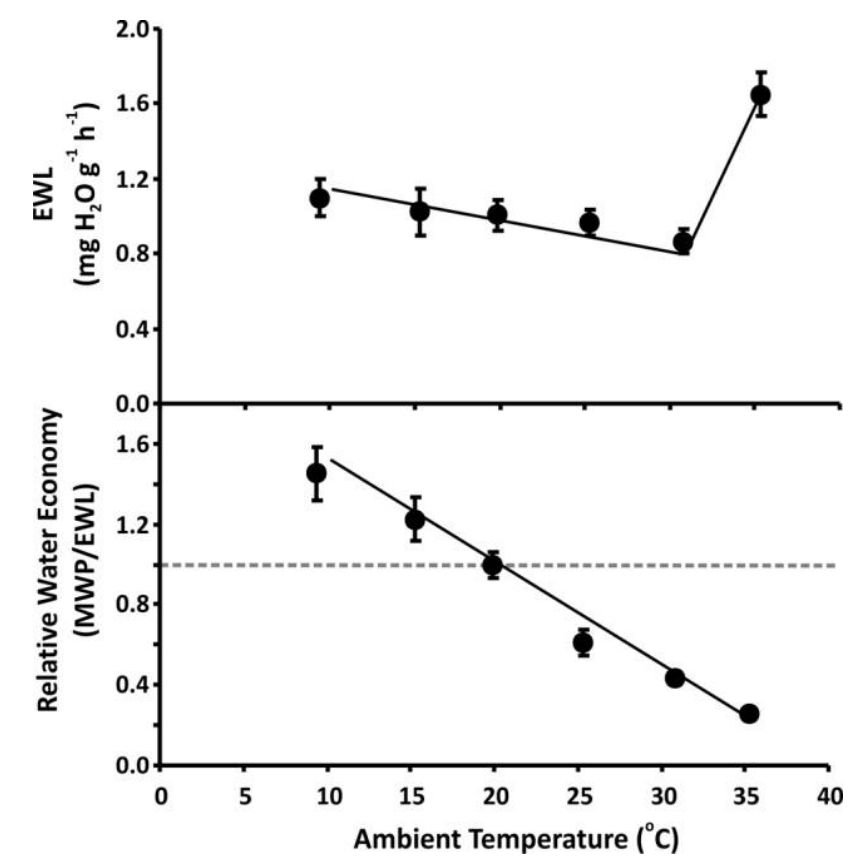

Figure 2. Evaporative water loss and relative water economy (metabolic water production/evaporative water loss) of dibblers (Parantechinus apicalis) at a range of ambient temperatures. Solid lines indicate patterns supported by a priori contrast analysis (see text). The dashed line indicates relative water economy $=1$. Values are mean \pm standard error; $N=8$. 


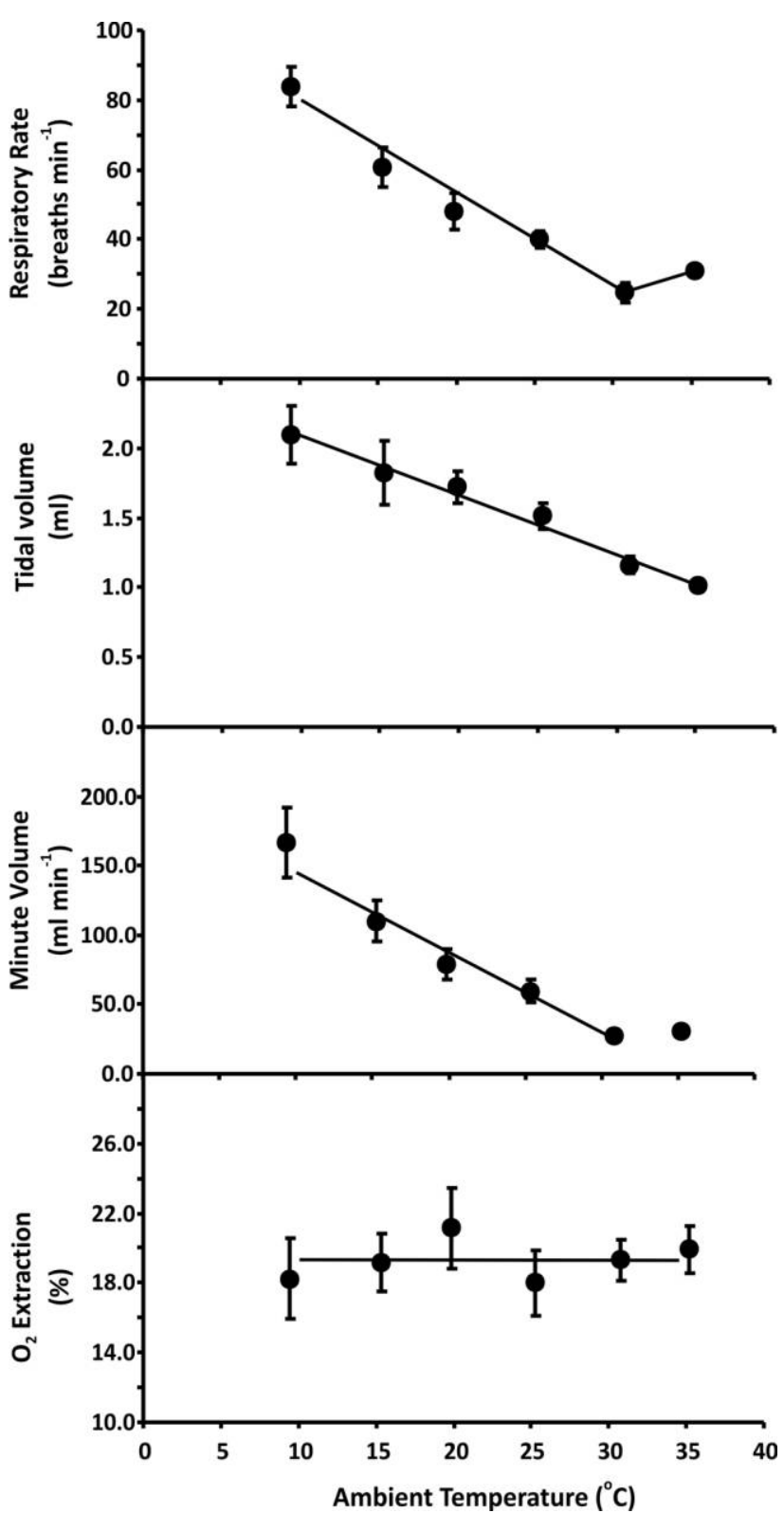

Figure 3. Ventilatory variables; respiratory frequency, tidal volume, minute volume, and oxygen extraction for dibblers (Parantechinus apicalis) at various ambient temperatures. Solid lines indicate patterns supported by a priori contrast analysis (see text). Values are mean \pm standard error; $N=8$.

not necessarily anticipated for these variables (e.g., Hinds and MacMillen 1986; Cooper and Withers 2002, 2004; Larcombe 2002; Withers and Cooper 2009a, 2009b). For any $T_{\text {a }}$ effects, it was of interest to establish what that pattern was and/or for which categories of the repeated factor there were significant differences. Although an absence of post hoc tests makes this difficult for MANOVAR, a priori contrasts provided a mechanism by which we could statistically describe the observed patterns of response to $T_{\mathrm{a}}$. A priori contrasts can also be valuable in examining specific hypotheses (e.g., a linear effect) even if the overall MANOVAR test is not significant. They are also useful for examining specific hypotheses in non-repeatedmeasures ANOVA and univariate repeated-measures ANOVA models.

For $T_{\mathrm{b}}$, the overall significant MANOVAR was supported by various significant a priori contrasts (polynomial, Helmert, reverse Helmert) that reflected a pattern of constant $T_{\mathrm{b}}$ from $T_{\mathrm{a}}=10^{\circ}$ to $31^{\circ} \mathrm{C}$ and then an increase in $T_{\mathrm{b}}$ above thermoneutrality $\left(T_{\mathrm{a}}=35^{\circ} \mathrm{C}\right)$. This pattern of $T_{\mathrm{b}}$ consistency at lower $T_{\mathrm{a}}$ and then hyperthermia at high $T_{\mathrm{a}}$ is expected for a euthermic mammal (e.g., McNab 1980; Withers 1992) and is consistent with that observed for other species of dasyurid marsupial (e.g., Robinson and Morrison 1957; Nicol and Maskrey 1980; Dawson and Dawson 1982; Geiser 1986; Schmidt et al. 2009; Cooper and Withers 2010). Many smaller dasyurid species are relatively thermolabile at low $T_{\mathrm{a}}$ (Morton and Lee 1978; Dawson and Wolfers 1978; Withers and Cooper 2009a, 2009b; Warnecke et al. 2010), but dibblers maintained a constant $T_{\mathrm{b}}$ below thermoneutrality and showed no tendency for torpor during experiments.

For $\mathrm{VO}_{2}$, the overall significant MANOVAR resulted from a slightly different pattern to $T_{\mathrm{b}}$, of a linear decrease in $\mathrm{Vo}_{2}$ with increasing $T_{\mathrm{a}}$ and then an increase at $T_{\mathrm{a}}=35^{\circ} \mathrm{C}$; there were significant differences between the thermoneutral $T_{\mathrm{a}}$ and all other $T_{\mathrm{a}}$ 's, and there was a significant quadratic relationship for $\mathrm{VO}_{2}$ at all $T_{\mathrm{a}}$ 's but only a linear relationship for $T_{\mathrm{a}}<35^{\circ} \mathrm{C}$. This is the expected pattern from the Scholander-Irving model for an endotherm (e.g., McNab 1980; Withers 1992), reflecting the increased metabolic heat production required for thermoregulation of a constant $T_{\mathrm{b}}$ at low $T_{\mathrm{a}}$, and it is typical of normothermic dasyurid marsupials (e.g., Nicol and Maskrey 1980; Geiser 1986; MacMillen and Dawson 1986; Schmidt et al. 2009; Withers and Cooper 2009a, 2009b; Cooper and Withers 2010; Warnecke et al. 2010). The predicted $T_{\mathrm{b}}$ from the relationship of $\mathrm{VO}_{2}$ with $T_{\mathrm{a}}$ below thermoneutrality of $36.2^{\circ} \mathrm{C}$ was very similar to the measured $T_{\mathrm{b}}\left(36.3^{\circ} \mathrm{C}\right)$, confirming the near conformity of dibblers to the Scholander-Irving model.

Similar use of a priori contrasts demonstrated the constancy of $C_{\text {wet }}$ and $C_{\text {dry }}$ at low $T_{\mathrm{a}}$ but elevated values at high $T_{\mathrm{a}}$. This pattern is typical for endotherms in general (e.g., McNab 1980; Withers 1992) and for other dasyurid marsupials in particular (Schmidt et al. 2009; Withers and Cooper 2009a, 2009b; Cooper and Withers 2010; Warnecke et al. 2010).

Ventilatory parameters of dibblers accommodated changing $\mathrm{O}_{2}$ demand with $T_{\mathrm{a}}$. The pattern of change in $V_{\mathrm{I}}$ with $T_{\mathrm{a}}$ mirrored that of $\mathrm{VO}_{2}$ and was mediated by a decrease in $f_{\mathrm{R}}$ with increasing $T_{\mathrm{a}}$ and then an increase at $T_{\mathrm{a}}=35^{\circ} \mathrm{C}\left(\right.$ like $\mathrm{Vo}_{2}$ ) and a linear decrease in $V_{\mathrm{T}}$. Such $f_{\mathrm{R}}$ and $V_{\mathrm{T}}$ changes are typical of similar-sized marsupials. Smaller species generally increase only $f_{\mathrm{R}}$ and larger species only $V_{\mathrm{T}}$ to increase $V_{\mathrm{I}}$ at low $T_{\mathrm{a}}$ (Hallam and Dawson 1993; Chappell and Dawson 1994; Schmidt et al. 2009; Withers and Cooper 2009b; Cooper and Withers 2010; Warnecke et al. 2010).

Even for EWL and $\mathrm{EO}_{2}$, for which the overall MANOVAR was insignificant, it was useful to examine specific a priori patterns. EWL of dibblers would be expected to increase at $T_{\mathrm{a}}$ 
above thermoneutrality as a thermoregulatory response when heat challenged (e.g., MacMillen and Dawson 1986; Schmidt et al. 2009; Withers and Cooper 2009a, 2009b; Cooper anc Withers 2010). We confirmed this response using polynomial contrasts including and excluding $T_{\mathrm{a}}=35^{\circ} \mathrm{C}$ and simple and reverse Helmert contrasts. The effect of lower $T_{\mathrm{a}}$ on EWL varies amongst dasyurids, from none to negative to positive (Hind:and MacMillen 1986; MacMillen and Dawson 1986; Cooper et al. 2005; Schmidt et al. 2009; Withers and Cooper 2009a, 2009b; Cooper and Withers 2010; Warnecke et al. 2010). Differences in patterns of change in the respiratory component of total EWL at low $T_{\text {a }}$ presumably contribute to this variation betweer $\rightarrow$ species. We found a significant negative effect of $T_{a} \leq 31^{\circ} \mathrm{C}$ for dibblers by linear contrast, and Helmert contrasts reinforced this interpretation. The negative EWL- $T_{\mathrm{a}}$ relationship for dibblers suggests that they have a relatively high respiratory EWL, presumably reflecting a comparatively poor nasal countercur $\rightarrow$ rent exchange system. Contrasts demonstrated the expected linear decrease in RWE with increasing $T_{a}$, and the PRWE of $20.3^{\circ} \mathrm{C}$ was consistent with that for other dasyurids (Schmidt et al. 2009; Withers and Cooper 2009a, 2009b; Cooper anc Withers 2010; Warnecke et al. 2010).

No a priori contrasts were significant for $\mathrm{EO}_{2}$, although we expected a decrease in $E_{2}$ to accompany increased $f_{\mathrm{R}}$ at higl $\rightarrow$ $T_{\mathrm{a}}$ (e.g., Cooper and Withers 2010). However, $f_{\mathrm{R}}$ only increased slightly (but $V_{\mathrm{I}}$ did not) for dibblers at $T_{\mathrm{a}}=35^{\circ} \mathrm{C}$, suggesting that $35^{\circ} \mathrm{C}$ was not sufficiently above the thermoneutral zone to initiate panting and decrease $\mathrm{Eo}_{2}$, consistent with results for some other dasyurids at a similar $T_{\mathrm{a}}$ (Chappell and Dawson 1994; Schmidt et al. 2009; Withers and Cooper 2009b).

We conclude that a priori contrasts, especially in conjunction with MANOVAR since post hoc tests are unavailable, provide a powerful statistical tool to examine expected patterns for repeated-measures physiological data. Judicious use of various a priori contrast tests for specific expected hypotheses providec considerably more information and power than just the overall MANOVAR hypothesis (that all means are equal), allowing us to statistically support the physiological patterns in respons $\rightarrow$ to changing $T_{\mathrm{a}}$ expected for the dibbler. It was found to be a typical endotherm, that closely conformed to the ScholanderIrving model, but was less thermolabile than many other small dasyurid marsupials.

\section{Acknowledgments}

We thank Perth Zoo, in particular Helen Robertson, Cath $\rightarrow$ Lambert, and the staff of the Native Species Breeding Program, for allowing us to measure the dibblers and for providing laboratory space. Cathy Lambert, Pat Woolley, and Harriet Mill: $\rightarrow$ provided comments on an earlier draft of the manuscript. This project was approved by the Animal Ethics Committees of the University of Western Australia (RA/3/100/528), Curtin Uni $\rightarrow$ versity (R52/2008), and Perth Zoo (approval 2008-2), and the research was funded by an Australian Research Council Discovery Grant to C.E.C. and P.C.W.

\section{Literature Cited}

Beaupre S.J. and F. Zaidan. 2001. Scaling of $\mathrm{CO}_{2}$ production in the timber rattlesnake (Crotalus horridus), with comments on cost of growth in neonates and comparative patterns. Physiol Biochem Zool 74:757-768.

$\rightarrow$ Berg A.M. and A.A. Biewener. 2008. Kinematics and power requirements of ascending and descending flight in the pigeon (Columba livia). J Exp Biol 211:1120-1130.

Bock R.D. 1975. Multivariate Statistical Methods in Behavioral Research. McGraw-Hill, New York.

Chappell M.A. and T.J. Dawson. 1994. Ventilatory accommodation of changing oxygen consumption in dasyurid marsupials. Physiol Zool 67:418-437.

Cohen B.H. 2008. Explaining Psychological Statistics. Wiley, Hoboken, NJ.

Cooper C.E., F. Geiser, and B. McAllan. 2005. Effect of torpor on the water economy of an arid-zone dasyurid, the stripefaced dunnart (Sminthopsis macroura). J Comp Physiol B 175:323-328.

Cooper C.E. and P.C. Withers. 2002. Metabolic physiology of the numbat (Myrmecobius fasciatus). J Comp Physiol B 172: $669-675$.

$\rightarrow$ 2004. Ventilatory physiology of the numbat (Myrmecobius fasciatus). J Comp Physiol B 174:107-111.

- 2010. Comparative physiology of Australian quolls (Dasyurus; Marsupialia). J Comp Physiol 180:857-868.

Cronin L. 2008. Cronin's Key Guide Australian Mammals. Jacana Crow's Nest, New South Wales.

Dawson T.J. and W.R. Dawson. 1982. Metabolic scope in response to cold of some dasyurid marsupials and Australian rodents. Pp. 255-260 in M. Archer, ed. Carnivorous Marsupials. Royal Zoological Society of New South Wales, Sydney.

$\rightarrow$ Dawson T.J. and J.M. Wolfers. 1978. Metabolism, thermoregulation and torpor in shrew sized marsupials of the genus Planigale. Comp Biochem Physiol 59:305-309.

Dunlap K.D., B.T. DiBenedictus, and S.R. Banever. 2010. Chirping response of weakly electric knife fish (Apteronotus leptorhynchus) to low-frequency electric signals and to heterospecific electric fish. J Exp Biol 213:2234-2242.

$\rightarrow$ Dupont-Prinet A., B. Chatain, L. Grima, M. Vandeputte, G. Claireaux, and D.J. McKenzie. 2010. Physiological mechanisms underlying a trade-off between growth rate and tolerance of feed deprivation in the European sea bass (Dicentrarchus labrax). J Exp Biol 213:1143-1152.

Geiser F. 1986. Thermoregulation and torpor in the kultarr, Antechinomys laniger (Marsupialia: Dasyuridae). J Comp Physiol B 156:751-757.

Geiser F. and R.V. Baudinette. 1988. Daily temperature and thermoregulation in the small dasyurid marsupials Planigale gilesi and Ningaui yvonneae. Aust J Zool 36:473-481.

Gilmour K.M., S.F. Perry, N.J. Bernier, R.P. Henry, and C.M. Wood. 2001. Extracellular carbonic anhydrase in the dogfish, Squalus acanthias: a role in $\mathrm{CO}_{2}$ excretion. Physiol Biochem Zool 74:477-492. 
$\rightarrow$ Gomez N.A., M. Acosta, F. Zaidan, and H.B. Lillywhite. 2006. Wiping behavior, skin resistance, and the metabolic response to dehydration in the arboreal frog Phyllomedusa hypochondrialis. Physiol Biochem Zool 79:1058-1068.

$\rightarrow$ Hallam J.F. and T.J. Dawson. 1993. The pattern of respiration with increasing metabolism in a small dasyurid marsupial. Respir Physiol 93:305-314.

Hand D.J. and C.C. Taylor. 1987. Multivariate Analysis of Variance and Repeated Measures. Chapman \& Hall, London.

$\rightarrow$ Hinds D.S. and R.E. MacMillen. 1986. Scaling of evaporativi $\rightarrow$ water loss in marsupials. Physiol Zool 59:1-9.

$\rightarrow$ Larcombe A.N. 2002. Effects of temperature on metabolism, ventilation, and oxygen extraction in the southern brown bandicoot Isoodon obesulus (Marsupialia: Peramelidae) Physiol Biochem Zool 75:405-411.

MacMillen R.E. and T.J. Dawson. 1986. Energy and water metabolism of the kowari, Dasyuroides byrnei (Marsupialia: Dasyuridae), while resting and running. Aust Mamm 9:87-95.

$\rightarrow$ Malan A. 1973. Ventilation measured by body plethysmography in hibernating mammals and in poikilotherms. Respir Phys iol 17:32-44.

$\rightarrow$ McLean J.A. and J.R. Speakman. 2000. Effects of body mass and reproduction on the basal metabolic rate of brown longeared bats (Plecotus auritus). Physiol Biochem Zool 73:112121.

$\rightarrow$ McNab B.K. 1980. On estimating thermal conductance in endotherms. Physiol Zool 53:145-156.

- 2002. The Physiological Ecology of Vertebrates. Cornell University Press, Ithaca, NY.

Menkhorst P. and F. Knight. 2004. A Field Guide to the Mammals of Australia. Oxford University Press, South Melbourne.

$\rightarrow$ Morton S.R. and A.K. Lee. 1978. Thermoregulation and metabolism in Planigale maculata (Marsupialia: Dasyuridae). J Thermal Biol 3:117-120.

Nicol S.C. and M. Maskrey. 1980. Thermoregulation, respiration and sleep in the Tasmanian devil, Sarcophilus harrisii (Marsupialia: Dasyuridae). J Comp Physiol 140:241-248.

$\rightarrow$ Park E., M. Cho, and C.-S. Ki. 2009. Correct use of repeated measures analysis of variance. Korean J Lab Med 29:1-9.

$\rightarrow$ Potvin C., M.J. Lechowicz, and S. Tardif. 1990. The statistica $\rightarrow$ analysis of ecophysiological response curves obtained from experiments involving repeated measures. Ecology 71:13801400.

Rencher A.C. 2002. Methods of Multivariate Analysis. Wiley, $\rightarrow$ Zh Hoboken, NJ.

$\rightarrow$ Rezende E.L., M.A. Chappell, and K.A. Hammond. 2004. Cold- acclimation in Peromyscus: temporal effects and individual variation in maximum metabolism and ventilatory traits. J Exp Biol 207:295-305.

$\rightarrow$ Robinson K.W. and P.R. Morrison. 1957. The reaction to hot atmospheres of various species of Australian marsupial and placental animals. J Cell Comp Physiol 49:455-478.

$\rightarrow$ Robson D.S. 1959. A simple method for constructing orthogonal polynomials when the independent variable is unequally spaced. Biometrics 15:187-191.

Schmidt S., P.C. Withers, and C.E. Cooper. 2009. Metabolic, ventilatory and hygric physiology of the chuditch (Dasyurus geoffroii; Marsupialia, Dasyuridae). Comp Biochem Physiol A 154:92-97.

$\rightarrow$ Szewczak J.M. and F.L. Powell. 2003. Open-flow plethysmography with pressure-decay compensation. Respir Physiol Neurobiol 134:57-67.

Warnecke L., C.E. Cooper, F. Geiser, and P.C. Withers. 2010. Environmental physiology of a small marsupial inhabiting arid floodplains. Comp Biochem Physiol A 157:73-78.

$\rightarrow$ Withers P.C. 1977. Metabolic, respiratory and haematological adjustments of the little pocket mouse to circadian torpor cycles. Respir Physiol 31:295-307.

- 1992. Comparative Animal Physiology. Saunders, Philadelphia.

$\rightarrow$ - 2001. Design, calibration and calculation for flowthrough respirometry systems. Aust J Zool 49:445-461.

$\rightarrow$ Withers P.C. and C.E. Cooper. 2009a. The metabolic and hygric physiology of the little red kaluta. J Mamm 90:752-760.

- 2009b. Thermal, metabolic, hygric and ventilatory physiology of the sandhill dunnart (Sminthopsis psammophila; Marsupialia, Dasyuridae). Comp Biochem Physiol A 153:317-323.

Woolley P.A. 2008. Dibbler (Parantechinus apicalis). Pp. 65-66 in S. Van Dyck and R. Strahan, eds. The Mammals of Australia. Reed New Holland, Sydney.

Wu S.-H., L.-N. Zhang, J.R. Speakman, and D.-H. Wang. 2009. Limits to sustained energy intake. XI. A test of the heat dissipation limitation hypothesis in lactating Brandt's voles (Lasiopodomys brandtii). J Exp Biol 212:3455-3465.

Zerm N., D. Zinkler, and J. Adis. 2004. Oxygen uptake and local $\mathrm{Po}_{2}$ profiles in submerged larvae of Phaeoxantha klugii (Coleoptera: Cicindelidae), as well as their metabolic rate in air. Physiol Biochem Zool 77:378-389.

Zhao Z.J. and J. Cao. 2009. Effect of fur removal on the thermal conductance and energy budget in lactating Swiss mice. J Exp Biol 212:2541-2549. 